\title{
O cérebro do terrorista: concepções holísticas e o apanhado do conhecimento neuroanatômico e neurocientífico
}

\author{
Fabiano de Abreu Agrela Rodrigues ${ }^{1}$ \\ deabreu.fabiano@gmail.com
}

\begin{abstract}
RESUMO
A neurociência tem uma colaboração efetiva para o conhecimento do funcionamento cerebral embasando-se em sua neuroanatomia. O terrorismo são atos desumanos e violentos que podem estar relacionados com a estimulação neural, sobretudo no córtex pré-frontal onde os terroristas tem uma maior estimulação devido a constante doutrinação. Assim, os objetivos deste estudo de cunho qualitativo, exploratório e sistemático foi realizar uma breve revisão sobre como funciona o cérebro de um terrorista bem como, a contribuição da neurociência para tal compreensão. Os materiais foram levantados em bases de dados online. É prudente acreditar que estes indivíduos tenham uma maior estimulação neural, sobretudo nos lideres e que os doutrinados sejam moldados culturalmente dentro de um fundamentalismo o que lhes dá uma satisfação em cometerem tais atos.
\end{abstract}

Palavras-chave: terrorismo; fundamentalismo; SNC; doutrinação.

\footnotetext{
${ }^{1} \mathrm{PhD}$, neurocientista, mestre psicanalista, biólogo, historiador, antropólogo, com formações também em neuropsicologia, psicologia, neurolinguística, neuroplasticidade, inteligência artificial, neurociência aplicada à aprendizagem, filosofia, jornalismo e formação profissional em nutrição clínica - Diretor do Centro de Pesquisas e Análises Heráclito; Chefe do Departamento de Ciências da Logos University; Membro da Federação Européia de Neurociências e da Sociedade Brasileira e Portuguesa de Neurociências. Universidades em destaque: Logos University, Nova de Lisboa, Faveni, edX Harvard, Universidad de Madrid.
} 


\title{
The brain of the terrorist: holistic conceptions and the collection of neuroanatomical and neuroscientific knowledge
}

\begin{abstract}
Neuroscience has an effective contribution to the knowledge of brain functioning based on its neuroanatomy. Terrorism is inhumane and violent acts that can be related to neural stimulation, especially in the prefrontal cortex where terrorists have greater stimulation due to constant indoctrination. Thus, the objectives of this qualitative, exploratory and systematic study were to carry out a brief review of how a terrorist's brain works, as well as the contribution of neuroscience to such understanding. The materials were collected from online databases. It is prudent to believe that these individuals have greater neural stimulation, especially in leaders, and that those indoctrinated are culturally molded within a fundamentalism, which gives them a satisfaction in committing such acts.
\end{abstract}

Keywords: terrorism; fundamentalism; SNC; indoctrination.

Artículo recibido: 05 octubre. 2021 Aceptado para publicación: 02 noviembre 2021 Correspondencia: deabreu.fabiano@gmail.com Conflictos de Interés: Ninguna que declarar 


\section{INTRODUÇÃO}

O terrorismo é o uso de violência física ou psicológica com a finalidade de incutir medo e pânico e, normalmente, coordenado por uma organização fundamentalista. Para os terroristas julgamentos morais dependem do resultado das suas ações, portanto agem de forma a atender a demanda de um fundamento notadamente retrogrado. Há muito questionamento acerca de como funciona o cérebro de um terrorista.

Assim, o encéfalo é a cede de Sistema Nervoso Central (SNC), sendo responsável por inúmeras funções de regulação, memória, coordenação, percepção e de caracterização do organismo. Conecta-se, ainda, à medula espinhal que a é responsável pela condução das informações e pelo arco reflexo. No SNC, o cérebro é a parte responsável pelo humor, memória, inteligência, personalidade sendo estas características que tornam os seres humanos individuais (BEAR; CONNORS; PARADISO, 2002; CAPLAN, 2009; MARTINI; TIMMONS; TALLITSCH, 2009; MOREIRA, 2021).

Partido desse pressuposto de que o cérebro nos torna seres individuais, questiona-se se este órgão pode também dar aos seres humanos características que são consideradas socialmente desumanas, com a capacidade de cometer atos que são extremamente brutais e violentos contra alvos indefesos em prol da sua ideologia ou crença, no caso os atos terroristas.

Assim, as perguntas que norteiam tal pesquisa são: Como funciona o cérebro terrorista? As pessoas terroristas nascem terroristas ou são moldadas a serem?

Soares et al. (2020) consideram uma ausência de uma definição consensual para o conceito de terrorismo. Por sua vez, Jacob (2019), diz que apesar do problema semântico do conceito, tendo em vista sua abstração, não exime que o terrorismo é a expressão do terror social e terror generalizado o que exerce uma carga emocional muito intensa em quem escuta. De acordo com o dicionário Dicio [online] terrorismo é a [...] "Maneira de estabelecer uma vontade através do uso contínuo do terror"; "Utilização organizada e metódica da violência com propósitos políticos, normalmente por meio de atentados, buscando desorganizar a sociedade vigente.” (DICIO, 2021, p. 01).

Assim, a compreensão, através de um estudo revisional é de grande importância, para agrupar de forma sistemática as principais pesquisas sobre o funcionamento no cérebro de um terrorista a nível neurobiológico e social, sendo, portanto, o objetivo deste estudo, que especificamente buscou traçar um breve histórico sobre o terrorismo mundial, além 
de buscar compreender através de uma revisão de literatura como funciona o cérebro de um terrorista a partir das bases teóricas da neuroanatomia e da neurociência.

\section{METODOLOGIA}

Esta pesquisa revisional categoriza-se de abordagem qualitativa do tipo básica, com objetivo exploratório e com o método de busca sistemático. Para tanto foram buscadas as informações nas seguintes bases de dados: Google Acadêmico, Scielo, PubMed e Lilacs buscando-se artigos, livros e monografias preferencialmente publicadas entre os anos de 2011 a 2021, em português e inglês. O levantamento de dados ocorreu nos meses de agosto e setembro de 2021.

\section{O Terrorismo e sua nefasta história}

Aa analisar a base teórica de publicações sobre o terrorismo em sites de busca como: Google Acadêmico, Scielo, PubMed, Lilacs, dentre outras, percebe-se que o tema teve uma enorme ascensão a partir de 11 de setembro de 2011, em virtude dos ataques às Terres Gêmeas onde dois aviões comerciais sequestrados foram lançados contra dois edifícios em Nova York, matando cerca de 3 mil pessoas. Tal atentado foi assumido pelo grupo fundamentalista religioso Al-Qaeda, que, na época, era liderado por Osama Bin Laden. Porém, apesar da grande repercussão o terrorismo tem um histórico mais antigo. Neste interim Ramos e Dos Santos Figueiredo (2012, p. 196) dissertam que:

Atentados que disseminam o terror não são algo novo na história da humanidade. A palavra terrorismo remonta à Revolução Francesa, ao terror dos jacobinos e de suas guilhotinas. $\mathrm{Na}$ acepção atual, é um fenômeno que começou no final do século XIX quando os anarquistas começaram a jogar bombas, tornando-se instrumento corriqueiro após a Segunda Guerra Mundial, visando a obter resultados políticos através da criação de situações de pânico coletivo. Um valor disfórico presente em ações de terror é a intimidação da sociedade civil, seja ela executada pelo governo ou grupos insurgentes.

Ainda complementam que já existia terrorismo na republica romana até fins do século XVIII a chamada "guerra destrutiva" ou "guerra punitiva". Na Grécia antiga aconselhavase a prática de assassinatos em países adversários para criar pânico. 
Mondaine (2004) complementa que no século XIX, a vocábulo "terrorismo" ganha uma positividade no movimento anarquista como forma de enfraquecer e destruir o poder estatal. No início do século XX percebe-se, de acordo com os estudos de Ramos e Dos Santos Figueiredo (2012), um agravo da violência internacional sendo o precedente histórico do terrorismo atual.

De acordo com o excerto de Costa (2018) o processo da globalização teve deveras contribuição para a projeção do terrorismo em escala global devido à exposição midiática e ao processo empático para os adeptos ao fundamentalismo religioso e os neoanarquistas que tem se propagado secularmente, com destaque para o mundo islâmico que em busca de sua Jihad Islâmica, ainda praticam atos extremos de terror e violência, especialmente com mulheres.

Rodrigues (2021) complementa que com a evolução do cérebro e consequentemente da inteligência e da lógica, o panorama mundial de conhecimento mudou o que não acontece com os grupos fundamentalistas-terroristas, ou seja, sua cultura lhes moldam e sua crença dominam suas habilidades cognitivas.

Assim, o terrorismo não é algo novo, todavia é extremamente perigoso para quem sofre e para quem o pratica, pois notadamente afeta diretamente o sistema nervoso de ambos.

\section{A NEUROANTAMIA E NEUROCIÊNCIA E SEU PERCURSO HISTÓRICO E CONCEITUAL}

O pensamento científico ficou por séculos "calado" pela sociedade medieval, sobretudo em por questões religiosas. No entanto, foi retomado de forma mais efetiva no século XVIII, em função da desinquietação de algumas mentes iluministas e questionadoras da época, assim, começou a ser aprofundado nos séculos XIX e XX, a partir publicações que desvinculavam a ciência do pensamento teológico prevalente da época. Cientistas como Francesco Redi, Louis Pasteur e Charles Darwin, trouxeram à luz o pensamento que os organismos não são criados ao acaso, que evoluem em processo seletivo e, que nada estaria ligado a pensamentos fixistas.

Assim, muitas hipóteses começaram a serem testadas em várias áreas e, algumas pesquisas sobre o sistema nervoso tiveram seu início nesta época através de técnicas anatômicas de dissecação de animais e humanos.

Cabe ressaltar que anatomia não é uma ciência recente segundo Batigália (2010), na história da anatômica o cientista e artista Leonardo da Vinci (1452-1519 d.C.) já fazia 
estudos onde associava a ciência e o desenho artístico. O termo anatomia tem origem grega, o que significa cortar em partes (KÖNIG; LIEBICH, 2002; DYCE, SACK, WENSING, 2004). Equivale-se à morfologia (do grego morphe, forma + logos, razão, estudo) (HILDEBRAND, 1995).

Ademais, a Neuroanatomia é ramo da anatomia que se dedica ao estudo da anatomia e fisiologia do sistema nervoso Central e Periférico, todavia nos últimos anos tem se ampliado, não apenas como um conhecimento biológico, e sim como uma grande área do conhecimento a Neurociência que pesquisa sobre o cérebro a e sua capacidade de aprender, ensinar, guardar e processar informações, além do como os organismos comportam-se e são capazes de influenciar e de serem influenciados, portanto é uma ciência em constante ampliação que não se finda em si. Georgeto et al. (2018) fizerem uma cronologia da evolução do conhecimento neuroanatômico: da antiguidade ao pósrenascimento demonstrando que é um ciência em constante evolução.

O cérebro apesar de, no ponto de vista anatômico, ser praticamente igual em todos os seres humanos difere-se em alguns indivíduos com comportamentos antissociais e transtornos de personalidade (MORANA; STONE; ABDALLA-FILHO, 2006), e segundo as mesmas autoras, ainda há diferenças entre os diversos comportamentos de diversos transtornos específicos de personalidade. Eles não citaram sobre o "cérebro terrorista" em seu estudo.

Por sua vez, a Neurociência em seu aspecto mais amplo, trouxe e vem trazendo, grandes contribuições para diversas áreas do conhecimento, evidenciando como o cérebro aprende, e se comporta. De acordo com Sierra fitzgerald e Munévar, (2007, p. 22) a [...] "neurociência cognitiva é a parte da ciência que procura entender como cérebro dá lugar às atividades mentais [...]”, inclusive de aprendizado de capacidade boas e ruins.

O Cérebro tem plasticidade neural o que lhe permite aprender constantemente. Relvas (2011) apresenta a definição de plasticidade neural como sendo a capacidade de adaptação do SNC e sua disposição para transformar seu arranjo estrutural próprio e funcionamento. Ou seja, é a propriedade que permite ao SNC se desenvolver e responder a estímulos, sobretudo no córtex pré-frontal.

\section{O CÉREBRO DO TERRORISTA}

Como dito, existem evidências de que anormalidades cerebrais podem estar relacionadas com o aparecimento de comportamentos parecidos aos dos psicopatas. Porém, com 
relação ao cérebro dos terroristas a ciência ainda está divergente (GOMES, DE ALMEIDA, 2010).

Em afirmação ao supracitado Konkiewitz (2010) e Rodrigues (2021) apresentam que as distintas regiões do cérebro têm funções específicas. O sistema límbico é a região relacionada com a emoção, assim disfunções nessa área acarretam perturbações, transtornos, síndromes, entre outros acometimentos mentais. Por sua vez, o córtex préfrontal é responsável pela inteligência, tomada de decisões, raciocínio, pela lógica e pelo comportamento social e sua disfunção pode acarretar em atos incoerentes e impulsivos.

Assim, o sujeito que tem estas áreas do cérebro preservadas, consideradas anatomicamente normais é capaz de ter a consciência, raciocínio lógico, tomar decisões prevendo as consequências de forma lúcida, sendo inclusive, o maior fator evolutivo dos humanos em se comparado com outros mamíferos que é o desenvolvimento do lobo frontal do cérebro. Todavia, as ações instintivas, também, envolvem o sistema límbico que dá ao ser humano a precaução, a sobrevivência, o instinto reprodutivo, ansiedade dentre outros aspectos de sobrevivência (BARRETO, SILVA, 2010; RODRIGUES, 2021).

Alguns estudos foram publicados sobre estudos acerca da mente e do cérebro do terrorista no que tange sua neurobiologia e psicologia destaca-se o estudo de Meixner e Rosenfeld (2001) da Northwestern University.

Meixner e Rosenfeld (2001) mostraram em seu estudo que é possível usar scanners cerebrais para prever um ataque terrorista ou identificar quem está prestes a cometer um crime. O estudo contemplou 02 pesquisadores e 29 estudantes de psicologia da Northwestern University, onde através de um programa computacional simularam o planejamento de um ataque terrorista a uma cidade dos Estados Unidos. Assim, os participantes voluntários receberam informações sobre o atentado terrorista fictício com dados como armas e bombas que seriam usadas. Para registar tiveram que anotar em cartas sua parte do plano.

Posteriormente os voluntários foram submetidos a um teste com eletrodos cerebrais para medir suas ondas P300, que é um tipo de onda que mede a atividade cortical que incide quando informações importantes são exibidas para uma pessoa que tem "conhecimento de culpa". 
Meixner e Rosenfeld (2001) concluíram que a codificação do conhecimento de culpa era existente, porém superficial, assim o estudo supõe que terroristas reais treinem repetidamente detalhes importantes para um ataque, levando a uma codificação mais profunda de memórias relacionadas, o que sugere a profunda "lavagem cerebral".

Torres (2002) apresenta em seu texto "O Cérebro das Operações: o terrorista de fato e de ficção" que o ato terrorista em si está mais associado com o aprendizado social e com a capacidade de "cérebros" de liderança em persuadirem os demais, notadamente a pessoa que comete um ato terrorista é desprovida de qualquer relação empática, porém não chega a ser um psicopata.

Soussumi (2006) e Rodrigues (2021), por sua vez, asseveram que o cérebro humano sempre busca a sobrevivência e também a sensação de benefício próprio com a sensação de recompensa que libera a dopamina permitindo o ser humano criar mapas mentais através de experiências arquivadas, assim é possível que o terrorista sinta prazer ao executar algum ato violento.

Existem dois tipos de terroristas, os que "se explodem e obedecem" ou aqueles que "lideram e mandam explodir", ou seja, existe um "cérebro" de planeja e um que executa. Um que é suficientemente perspicaz e frio para planejar e um que é suficientemente moldável e frio para seguir. Tais ações também se relacionam às regiões do córtex préfrontal. Portanto, de acordo com o autor, é oportuno acreditar que mais que uma alteração cerebral existe uma relação de servidão a uma ideologia fundamentalista que exige tais práticas (RODRIGUES, 2021).

Gonçalves e Reis (2017) acreditam que os atos terroristas tenham: objetivos políticos; atos ilegais violentos ou ameaças ilegais violentas; ações conduzidas com o objetivo de produzir efeitos que extrapolem aqueles sobre as vítimas, com repercussões gerais; ações conduzidas por organizações não estatais ou grupos. Acrescentam ainda que [...] "o comportamento de grupos terroristas é, portanto, racional, apesar de se pensar sobre a irracionalidade de tais atos, devido às desgraças proporcionadas e à utilização excessiva da violência" (GONÇALVES e REIS, 2017, p. 13-14).

Bartol e Bartol (2014) dissertam que os terroristas demonstram ser mais estáveis que outros tipos de delinquentes violentos. Isso se torna mais claro, para eles, devido à hierarquia e disciplina necessária para organizar e executar os atentados. Para eles 
indivíduos com transtornos mentais não conseguiriam se tornar terroristas, pois não teriam condições de planejar, obedecer ao grupo fundamentalista.

\subsection{Discussão}

Do ponto de vista das ações terroristas, infere-se que os líderes são mais inteligentes, ou seja, seu córtex pré-frontal é mais bem desenvolvido, tendo em vista estarem na posição de liderança. O que de acordo com Woolgar et al. (2010) asseveram que existem correlações positivas entre estímulos ao córtex pré-frontal e liderança, sugerindo que esta região cerebral mais estimulada ocasiona um melhor desempenho cognitivo, ainda que o tal característica pode estar ligada a questões hereditárias.

Assim, no terrorismo existem os que doutrinam, por aparentemente terem seu córtex préfrontal mais desenvolvido, e os são doutrinados desde jovens, por terem um menor conhecimento e crença religiosa definida, ainda em função de fatores culturais, educativos e religiosos que ampliam a possibilidade de doutrinação (WAINBERG, 2007; MOREIRA, JÚNIOR, 2017).

Dessa maneira, é prudente acreditar que os terroristas são motivados por paixão e um emaranhado de emoções e razões bem definidas vinculadas às concepções culturais e religiosas ligadas, ainda, aos neurotransmissores que trazem uma satisfação não encontrada em vida.

É no sistema límbico que se expressam as emoções no cérebro, portanto, a atividade excessiva nesta região pode fazer com que as experiências comuns adquiram um significado mais profundo e intenso, assim experiências fundamentalistas podem liberar grande quantidade de neurotransmissores e hormônios levando a uma situação êxtase (SPINELLA; WAIN, 2018).

Portanto, há no terrorista e em suas ações o mecanismo de recompensa e realização pela liderança e vitória, devido à liberação de vários neurotransmissores dentre eles a dopamina e a serotonina que apresentam tanto efeitos inibitórios quanto estimulantes na agressividade, dependendo da região do cérebro (NARVAES, 2013).

Exemplificando: o terrorista local, Afegão, não tem estudo e, em via de regra, aprende a vida inteira que o fundamento religioso é o essencial para sua existência, este indivíduo acredita que encontrará a felicidade e a glória ao cometer o ato terrorista. São retrógrados de forma semântica, ou seja, a glória após morte são as únicas conquistas verdadeiras e sua a crença os fazem acreditar que encontrarão um lugar melhor do que aquele ruim que 
viveu toda a vida. A excitação que antecede o ato dá razão a uma vida difícil e infeliz, portanto a função neural e plástica desses indivíduos é moldada a crer que a expiação será sua redenção.

O terrorista de uma capital europeia, por exemplo, teve a chance de uma vida melhor. Mas a educação dos pais retrógrada e severa devido a crença religiosa, vem à tona quando o terrorista se vê isolado, excluído. Se sentir diferente onde vive não é bom, vive-se uma mágoa constante que se torna uma revolta e vingança. $\mathrm{O}$ ato em si é uma vingança por não ser aceito e por se sentir diferente. Quando na realidade queria ser igual.

\section{CONSIDERAÇÕES FINAIS}

Diante do levantamento aqui apresentado e, diante da síntese realizada na busca sistemática, respeitando-se as limitações de materiais publicados sobre o tema, considerase, ponto finalizando, que o não existe um único fator para a existência do terrorismo, sendo este uma ocorrência muito complexa além de que sua história e, até mesmo, seus conceitos são divergentes.

Conclui-se, ainda, que a neuroanatomia, bem como a neurobiologia e neurociência são áreas do conhecimento que muito podem colaborar para o conhecimento sobre o cérebro do terrorista.

Os apontamentos aqui encontrados demonstraram que os terroristas são seres que tem sua mente mais ligada a servir a um grupo fundamentalista do que propriamente dito há uma disfunção neurológica e, que o terrorista é um ser psicologicamente motivado devido a fatores fundamentalistas, sobretudo, religiosos.

Estudos acerca do cérebro dos terroristas ainda são insipientes, todavia os que foram elencados são científicos com métodos eficazes, porém há ainda uma importante lacuna em pesquisas mais específicas, sobretudo neste momento histórico em que o grupo fundamentalista Talibã tomou o controle do Afeganistão causando grande temor interno e internacional.

Por fim, acredita-se que o terrorista mesmo tendo novas oportunidades fixa-se em sua educação doutrinadora e vê-se muitas vezes isolado e trazendo-lhe um sentimento de mágoa constante que se torna uma revolta e vingança. $\mathrm{O}$ ato em si é uma vingança por não ser aceito e por se sentir diferente. Os estudos aqui pesquisados demostram que a neurociência tem subsídios para demonstrar que o cérebro de um terrorista especialmente o dos lideres tem uma estimulação neurotransmissora mais efetiva. 


\section{REFERÊNCIAS}

BARRETO, J. E. F.; SILVA, L. P. Sistema Límbico E As Emoções - Uma Revisão Anatômica. Revista Neurociências. S.L. V.18, N.3, p.386-394. 2010

BATIGÁLIA, F. Técnicas filosóficas no aprendizado anatômico. Revista de Divulgação

Científica da Sociedade Brasileira de Anatomia, ano 1, v. 1, jan. 2010.

BARTOL, C. R.; BARTOL, A. M. Criminal behavior: A psychological approach. Upper Saddle River, NJ: Pearson, 2014.

BEAR, M. F.; CONNORS, B. W.; PARADISO, M. A. Neurociências: desvendando o sistema nervoso. Artmed editora, 2002.

CAPLAN L.R., Caplan's stroke: a clinical approach, 4a edição, Philadelphia, Elsevier Inc., 2009.

COSTA, Marina Gentil da.Terrorismo: evolução histórica e emergência do ISIS. 2018. 33 f. Dissertação (Mestrado) - Curso de Especialização em Relações Internacionais, Relações Internacionais, Unb, Brasilia, 2018. Disponível em: https://bdm.unb.br/bitstream/10483/24342/1/2018_MarinaGentilDaCosta_tcc.pd f. Acesso em: 03 set. 2021.

DICIO, Dicionário Online de Português. Terrorismo, 2021. Disponível em: https://www.dicio.com.br/terrorismo/. Acesso em 04 de set. 2021.

DYCE, K. M.; SACK, M. O.; WENSING, C. J. G. Tratado de anatomia veterinária. 3 ed. Rio de Janeiro: Elsevier, 2004.

GEORGETO, S. M.; ZICIARELL, C. A. M.; AGUIAR, L. R.; GARIBA, M. A.; FERNANDES, K. B. P.; COLIONE, A. G. G.; PESENTE, F. S.; SAMPAIO, M. G. Evolução Cronológica do Conhecimento Neuroanatômico: Da Antiguidade ao pós-Renascimento - Parte 1. JBNC - JORNAL BRASILEIRO DE NEUROCIRURGIA, v. 25, n. 2, p. 127 - 135, 26 mar. 2018.

GOMES, C. C.; DE ALMEIDA, R. M. M. Psicopatia em homens e mulheres. Arquivos brasileiros de Psicologia, v. 62, n. 1, p. 13-21, 2010.

GONÇALVES, J.B.; REIS, M.V. Terrorismo: conhecimento e combate. Impetus, Niterói, v. 2, n. p.. 45-55, 2017.

HILDEBRAND, M. Análise da Estrutura dos vertebrados. São Paulo: Atheneu, 1995. p. 263. 
JACOB, B. T. O conceito de terrorismo em Igor Primoratz. In: VIESENTEINER, J.L ; BARBOSA, M. T. Deleuze, Desconstrução e Alteridade, São Paulo: ANPOF, p.197. 2019.

KONKIEWITZ, E. C. Tópicos de neurociência clínica. Coleção Cadernos Acadêmicos, $1^{\circ}$ ed. UFG, 2010.

KÖNIG, H. E.; LIEBICH, H. G. Anatomia dos animais domésticos: texto e atlas colorido. Porto Alegre: Artmed, 2002. v. 1.

MARTINI, F. H.; TIMMONS, M. J.; TALLITSCH, R. B. Anatomia Humana-: Coleção Martini. Artmed Editora, 2009.

MARTINS, J. C. L.; DE ALMEIDA, I. N. S. Contribuições da neurociência cognitiva para a educação no ensino superior. Humanidades \& Inovação, v. 6, n. 9, p. 225$232,2019$.

MEIXNER, J. B., ROSENFELD, J. P. A mock terrorism application of the P300-based concealed information test. Psychophysiology, S.L., v.48, n.2, p.149-154. 2011. https://doi.org/10.1111/j.1469-8986.2010.01050.x

MORANA, H. C. P; STONE, M. H.; ABDALLA-FILHO, E.. Transtornos de personalidade, psicopatia e serial killers. Brazilian Journal of Psychiatry, v. 28, p. s74-s79, 2006.

MOREIRA, R, P.; JUNIOR, E. R. C. O fenômeno terrorismo: entendendo a violência e os objetivos de um terrorista. O Alferes, v. 27, n. 71, 2017.

MOREIRA, A. C. M. et al. Prossecção de peças de encéfalos humanos para estudo neuroanatômico em cursos médicos. Brazilian Journal of Development, v. 7, n. 5, p. 47354-47360, 2021.

NARVAES, Rodrigo Furini. Comportamento agressivo e três neurotransmissores centrais: dopamina, gaba e serotonina: uma revisão sistemática dos últimos 10 anos. 2013.

RAMOS, E. C. M.; DOS SANTOS FIGUEIREDO, W.. Terrorismo: Um Legado Histórico E Sua Caracterização Na Plataforma Midiática. Ciência Geográfica Bauru - XVI - Vol. XVI- (2): Janeiro/Dezembro - 2012 p. 195.

RELVAS, M. P. Neurociência e transtornos de aprendizagem: as múltiplas eficiências para uma educação inclusiva. 5. ed. Rio de Janeiro: Wak Ed, 2011. 
RODRIGUES, F. A. Como funciona o cérebro de um terrorista. Impala News, S.L, v. 5 , n. $1, \quad$ p. $1-2, \quad 2021 . \quad$ Disponível em: https://www.impala.pt/noticias/atualidade/como-funciona-o-cerebro-de-umterrorista/. Acesso em: 04 set. 2021.

SIERRA-FITSZGERALD, O.; MUNÉVAR, G. Nuevas ventanas hacia el cérebro humano y su impacto en la neurociencia cognoscitiva. Revista Latinoamericana de Psicologia, Bogotá, n.39, v.1, p.143- 157, 2007.

SOARES, H. et al. O nó górdio do ato terrorista: réplica ao conceito de terrorismo proposto por Adriano Teixeira. Revista de Estudos Criminais, v. 19, n. 78, p. 131-156, 2020.

SOUSSUMI, Yusaku. Tentativa de integração entre algumas concepções básicas da psicanálise e da neurociência. Psicologia clínica, v. 18, p. 63-82, 2006.

SPINELLA M.; WAIN, O. Las bases neurales de las creencias morales, religiosas y paranormales. Pensar: revista latino-americana para la ciencia y laá razón. S.L, v. 04, n. 02, p. 01-08, 2018. Disponível em: https://archives.centerforinquiry.org/pensar/las-bases-neurales-de-las-creenciasmorales-religiosas-y-paranormales/. Acesso em 06 de set. 2021

TORRES, S. O Cérebro das Operações: o terrorista de fato e de ficção. Matraga. Rio de Janeiro: Ed. Caetés, v. 14, p. 117-139, 2002.

WAINBERG, J. O poder das palavras e das idéias: o caso do fundamentalismo islâmico. Revista FAMECOS, S.L, v.14, n. 34, p. 14-123. 2007.

WOOLGAR, Alexandra et al. Fluid intelligence loss linked to restricted regions of damage within frontal and parietal cortex. Proceedings of the national academy of sciences, v. 107, n. 33, p. 14899-14902, 2010. 